\title{
Effects of Silica and Titanium Oxide Particles on a Human Neural Stem Cell Line: Morphology, Mitochondrial Activity, and Gene Expression of Differentiation Markers
}

Kouki Fujioka ${ }^{1}$, Sanshiro Hanada ${ }^{2}$, Yuriko Inoue ${ }^{3}$, Keisuke Sato ${ }^{4,5}$, Kenji Hirakuri ${ }^{4}$, Kouichi Shiraishi ${ }^{6}$, Fumihide Kanaya ${ }^{2}$, Keiichi Ikeda ${ }^{1}$, Ritsuko Usui ${ }^{1}$, Kenji Yamamoto ${ }^{2}$, Seung U. Kim ${ }^{7,8}$ and Yoshinobu Manome ${ }^{1, *}$

1 Division of Molecular Cell Biology, Core Research Facilities for Basic Science, The Jikei University School of Medicine, Tokyo 105-8461, Japan;

E-Mails: kfujioka@jikei.ac.jp (K.F.); ikedak@jikei.ac.jp (K.I.); ree-chicochamaro@jikei.ac.jp (R.U.)

2 Research Institute, National Center for Global Health and Medicine, Tokyo 162-8655, Japan; E-Mails: hanada@ri.ncgm.go.jp (S.H.); fkanaya@acc.ncgm.go.jp (F.K.); ykenji@hosp.ncgm.go.jp (K.Y.)

3 Department of Anatomy, Toho University, Tokyo 143-8540, Japan;

E-Mail: yuriko.inoue@med.toho-u.ac.jp

4 Department of Electrical and Electronic Engineering, Tokyo Denki University, Tokyo 120-8551, Japan; E-Mails: satok@mail.dendai.ac.jp (K.S.); hirakuri@mail.dendai.ac.jp (K.H.)

5 International Center for Materials Nanoarchitectonics, National Institute for Materials Science, Ibaraki 305-0044, Japan

6 Medical Engineering Laboratory, Research Center for Medical Science, The Jikei University School of Medicine, Tokyo 105-8461, Japan; E-Mail: kshiraishi@jikei.ac.jp

7 Medical Research Institute, Chung-Ang University College of Medicine, Seoul 440-746, Korea; E-Mail: sukim@mail.ubc.ca

8 Division of Neurology, Department of Medicine, University of British Columbia, Vancouver, BC V6T 2B5, Canada

* Author to whom correspondence should be addressed; E-Mail: manome@jikei.ac.jp; Tel.: +81-3-3433-1111; Fax: +81-3-3435-1922.

Received: 13 March 2014; in revised form: 25 May 2014 / Accepted: 16 June 2014 / Published: 2 July 2014

Abstract: Several in vivo studies suggest that nanoparticles (smaller than $100 \mathrm{~nm}$ ) have the ability to reach the brain tissue. Moreover, some nanoparticles can penetrate into the brains of murine fetuses through the placenta by intravenous administration to pregnant mice. 
However, it is not clear whether the penetrated nanoparticles affect neurogenesis or brain function. To evaluate its effects on neural stem cells, we assayed a human neural stem cell (hNSCs) line exposed in vitro to three types of silica particles (30 nm, $70 \mathrm{~nm}$, and $<44 \mu \mathrm{m}$ ) and two types of titanium oxide particles $(80 \mathrm{~nm}$ and $<44 \mu \mathrm{m})$. Our results show that hNSCs aggregated and exhibited abnormal morphology when exposed to the particles at concentrations $\geq 0.1 \mathrm{mg} / \mathrm{mL}$ for 7 days. Moreover, all the particles affected the gene expression of Nestin (stem cell marker) and neurofilament heavy polypeptide ( $\mathrm{NF}-\mathrm{H}$, neuron marker) at $0.1 \mathrm{mg} / \mathrm{mL}$. In contrast, only $30-\mathrm{nm}$ silica particles at $1.0 \mathrm{mg} / \mathrm{mL}$ significantly reduced mitochondrial activity. Notably, 30-nm silica particles exhibited acute membrane permeability at concentrations $\geq 62.5 \mu \mathrm{g} / \mathrm{mL}$ in $24 \mathrm{~h}$. Although these concentrations are higher than the expected concentrations of nanoparticles in the brain from in vivo experiments in a short period, these thresholds may indicate the potential toxicity of accumulated particles for long-term usage or continuous exposure.

Keywords: silica; titanium oxide; nano; toxicity; neural stem cell; neural progenitor cell; differentiation

\section{Introduction}

Recent technical advances have enabled mass production of various nanomaterials, such as silica, titanium oxide, and carbon nanotubes. Although these nanomaterials are currently used in products that directly contact the human body, e.g., cosmetics [1,2] and food [3,4], their safe usage is still under investigation. In particular, there is a concern that some characteristics of nanomaterials, such as their tube- or fiber-like structures with rigid properties or certain sizes, might cause toxicity similar to that of asbestos [5-7].

Both in vitro and in vivo studies of nanoparticles toxicity are currently in progress [8-13]. In vitro studies have revealed several cytotoxic mechanisms, such as (1) reactive oxygen species (ROS) generation by cells that uptake titanium oxide particles [14,15] or silicon/silica particles [16,17]; and (2) the release of metallic material from $\mathrm{Cd} / \mathrm{Se}$ quantum dots (QDs) after UV exposure [16] or silver particles [18]; and (3) structure-related toxicity caused by multi-walled carbon nanotubes [19]. Moreover, in vivo studies have revealed (1) alterations in blood components by the exposure of titanium oxide particles [20] or silver particles [21]; and (2) the distribution of QDs in several tissues [22-24].

Nanoparticles accumulation in brain tissue has also been described in many studies [22-29]. For example concerning QDs, intravenous injection of QDs coated with $-\mathrm{OH},-\mathrm{NH}_{2}$, or $-\mathrm{COOH}$ functional groups results in different rates of brain penetration [22]. Furthermore, in a pilot study, cadmium ion was slightly detected in the brain tissue of rhesus macaques after the injection of phospholipid micelle-encapsulated CdSe/CdS/ZnS QDs [24].

Other studies showed that the penetration of nanoparticles into the brain differs depending on their size $[21,29,30]$. The silver particles smaller than $100 \mathrm{~nm}(22,42$, and $71 \mathrm{~nm})$ have been demonstrated to penetrate into the murine brain, whereas $323-\mathrm{nm}$ particles have not been found in the murine 
brain [21]. Moreover, intravenous administration of 70-nm silica particles in pregnant mice resulted in placental penetration and accumulation in the fetal brain, whereas 300- and 1000-nm particles did not cross the placental-maternal barrier [29]. Our previous study also showed size-dependent penetration of silica particles with a blood-brain barrier model in vitro [30]. The apparent permeability coefficient (Papp) in the model for the $30 \mathrm{~nm}$ silica particles was higher than those of the larger silica particles $(100$ and $400 \mathrm{~nm})$ [30]. These reports indicate that some nanoparticles, especially the particles smaller than $100 \mathrm{~nm}$ have the potential to penetrate brain tissue.

However, few in vivo experiments have revealed how nanoparticles affect brain functions. Because in vivo assessment of brain functions involves many aspects, such as neural activity, brain tissue inflammation, and behavioral evaluation, it is difficult to evaluate the functional effects of a small number of particles on the brain.

Therefore, for evaluating the effects on neural development or brain function, we investigated the effects of nanoparticles on neural stem cells (NSCs). NSCs are precursor cells that develop into neurons and glial cells in the fetal brain during embryonic development [31]. Furthermore, recent reports indicated that NSCs also exist in the adult brain, specifically in the subventricular zone and the dentate gyrus of the hippocampus, and are responsible for neuronal regeneration [32,33]. Another study showed that high mobility group AT-hook (HMGA) proteins have been reported as a factor in fate transition or restriction of neural precursor cells [34]. Thus, the investigation of NSCs activity will be helpful in evaluating the effects of nanoparticles on neural development or brain function.

As for nanoparticles' effects on the human NSCs (hNSCs), a few in vitro studies using cell lines have been reported [35,36]. Song et al. showed that proliferations and viabilities of hNSCs were not affected by the co-culture of some superparamagnetic iron oxide nanoparticles (around 28/100 nm) at $25 \mu \mathrm{g} / \mathrm{mL}$ for $24 \mathrm{~h} \mathrm{[35].} \mathrm{In} \mathrm{another} \mathrm{study,} \mathrm{Söderstjerna} \mathrm{et} \mathrm{al.} \mathrm{reported} \mathrm{a} \mathrm{significant} \mathrm{effect} \mathrm{on} \mathrm{the}$ sphere size- and morphology of human embryonic neural precursor cells was found for all cultures exposed to gold and silver nanoparticles $(20 / 80 \mathrm{~nm})$ at 50 or 800 particles/cells, although these particles did not significantly affect the total number of living and dead cells [36]. Both studies investigated the effects at lower concentration ranges and left possibilities of further investigations for potential toxicity at higher concentrations.

In this study, we revealed toxicological effects and their threshold concentration of nanoparticles on human NSCs (hNSCs) line using three types of silica particles (SP), SP30 (30 nm), SP70 (70 nm), and SPM $(<44 \mu \mathrm{m})$, and two types of titanium particles (TP), TP80 $(80 \mathrm{~nm})$ and TPM $(<44 \mu \mathrm{m})$.

\section{Results}

\subsection{Physical Properties of Particles}

We studied the properties of SP30, SP70, SPM, TP80, and TPM particles. Scanning electron microscopy (SEM) showed that SP30 particles were uniform size and morphology, whereas the other particles appeared variable size or displayed agglomerated forms (Figure 1A). In addition, measurements of dynamic light scattering (DLS) revealed that the Z-average of dispersed SP30 in water was $28.5 \pm 0.03$ and its polydispersity index (PDI) $(0.116 \pm 0.011)$ was lower than other particles' PDI $(>0.223$ ), suggesting a narrower size distribution (Figure $1 \mathrm{~B}$ and Table 1$)$. On the other hand, the Z- 
average of dispersed SPM was $1322.7 \pm 112.9 \mathrm{~nm}$ and PDI was higher than other particles, suggesting a broader size distribution (Table 1). The other particles (SP70, TP80, and TPM) exhibited 208.5-671.9 in Z-average and 0.223-0.415 in PDI (Table 1). Surface charge data showed that all the particles possessed negative potentials from -26.9 for SP30 to -60.6 for SP70 (Table 1).

Figure 1. (A) SEM images of the particles; (B) size distribution histogram of the particles in Milli-Q water (Mean \pm S.D., $n=3)$; and $(\mathbf{C})$ dispersity in Milli-Q water $(1.0 \mathrm{mg} / \mathrm{mL})$.

(A) SEM

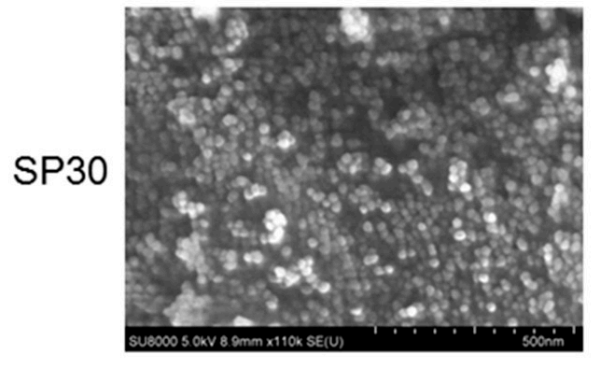

SP70

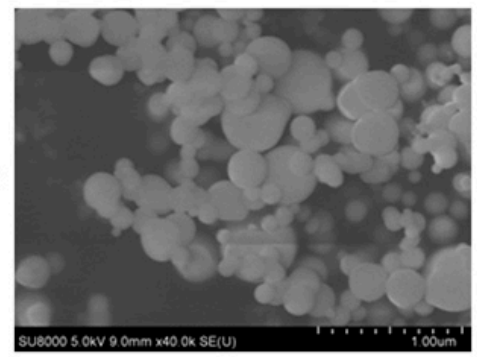

SPM

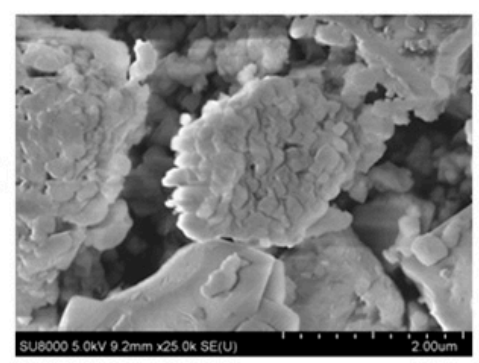

TP80

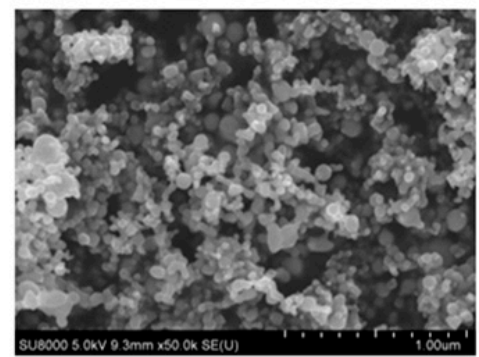

TPM

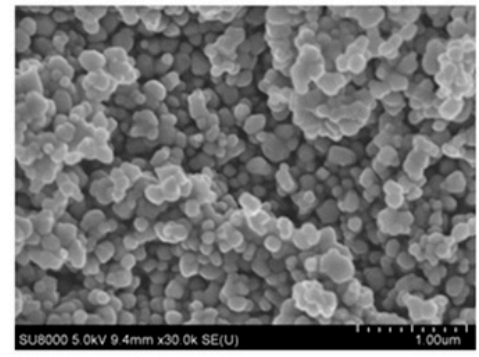

(B) DLS in Milli-Q Water
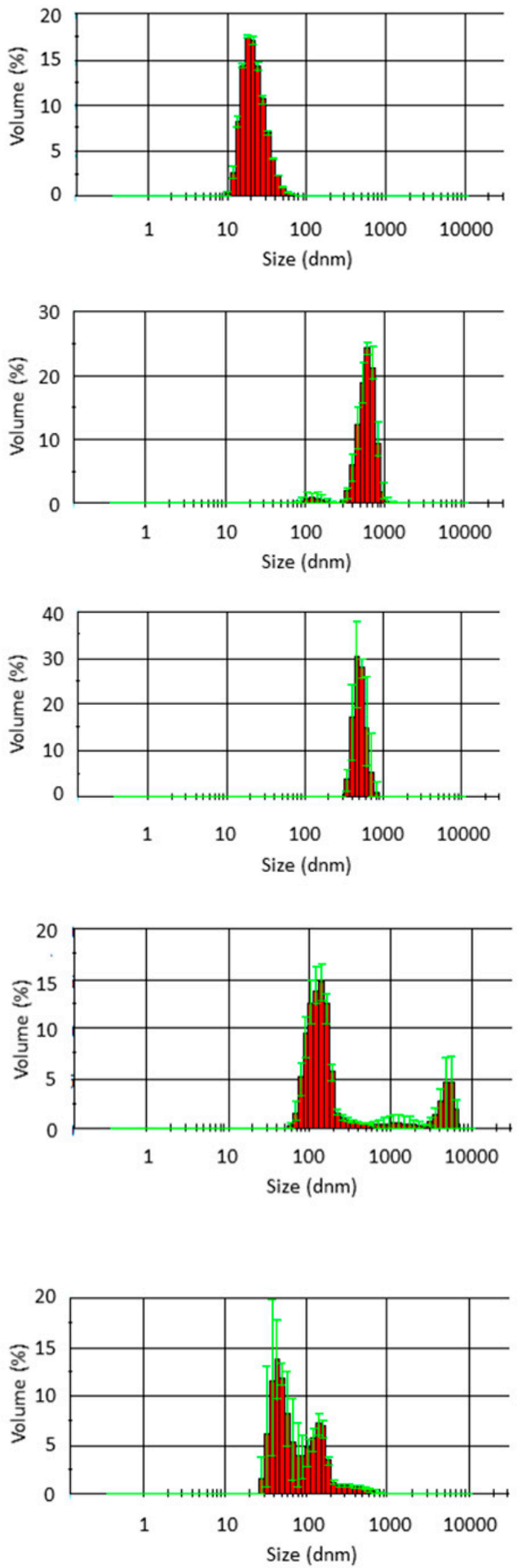

(C) Dispersity in Milli-QWater

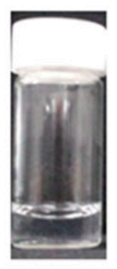

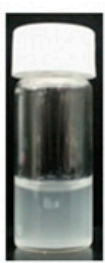
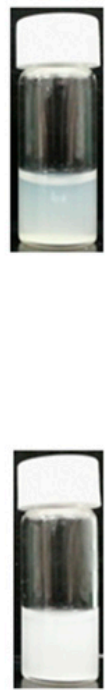
SP30 exhibited higher dispersity in Milli-Q water than other particles, and no aggregation was observed (Figure 1C). On the other hand, other particles exhibited less dispersity, in particular, SP70 exhibited agglomeration and sedimentation.

Table 1. Physical properties of the dispersed particles in Milli-Q water (supernatant). These data shows mean \pm S.D. of two or three measurements.

\begin{tabular}{cccc}
\hline Particles & Z-Average in Diameter $(\mathbf{n m})$ & PDI & Zeta Potential \\
\hline SP30 & $28.5 \pm 0.03$ & $0.116 \pm 0.011$ & $-26.9 \pm 0.2$ \\
SP70 & $671.9 \pm 13.0$ & $0.415 \pm 0.028$ & $-60.6 \pm 1.3$ \\
SPM & $1322.7 \pm 112.9$ & $0.698 \pm 0.263$ & $-35.3 \pm 0.3$ \\
TP80 & $208.5 \pm 4.3$ & $0.264 \pm 0.030$ & $-36.2 \pm 0.1$ \\
TPM & $210.6 \pm 4.7$ & $0.223 \pm 0.009$ & $-44.1 \pm 1.4$ \\
\hline
\end{tabular}

\subsection{Morphological Effects and Mitochondrial Activity}

We exposed hNSCs to the particles (concentration: $0.01,0.1$, and $1.0 \mathrm{mg} / \mathrm{mL}$ ) for 7 days. In the control group, which was cultured in normal medium, almost no cellular aggregations and morphological abnormalities were observed (Figure 2A). In contrast, by day 7, all groups exposed to particles at concentrations $\geq 0.1 \mathrm{mg} / \mathrm{mL}$ showed cellular aggregation and morphological abnormalities, such as shrinking or swelling (Figure 2B-F).

Figure 2. Observation of hNSCs exposed to particles for 7 days. Orange frames indicate cellular aggregation or morphological abnormalities. (A) Control; (B) FL-SP30; (C) SP70; (D) SPM; (E) TP80; and (F) TPM. In the Figure (B), bright-field images (upper) and fluorescent images (lower) exhibit. Since many FL-SP30 attached to the basement of the plate at $1.0 \mathrm{mg} / \mathrm{mL}$, brightness of the fluorescent images (lower) at $1.0 \mathrm{mg} / \mathrm{mL}$ was reduced by $50 \%$. Scale bar (white) indicates $100 \mu \mathrm{m}$.
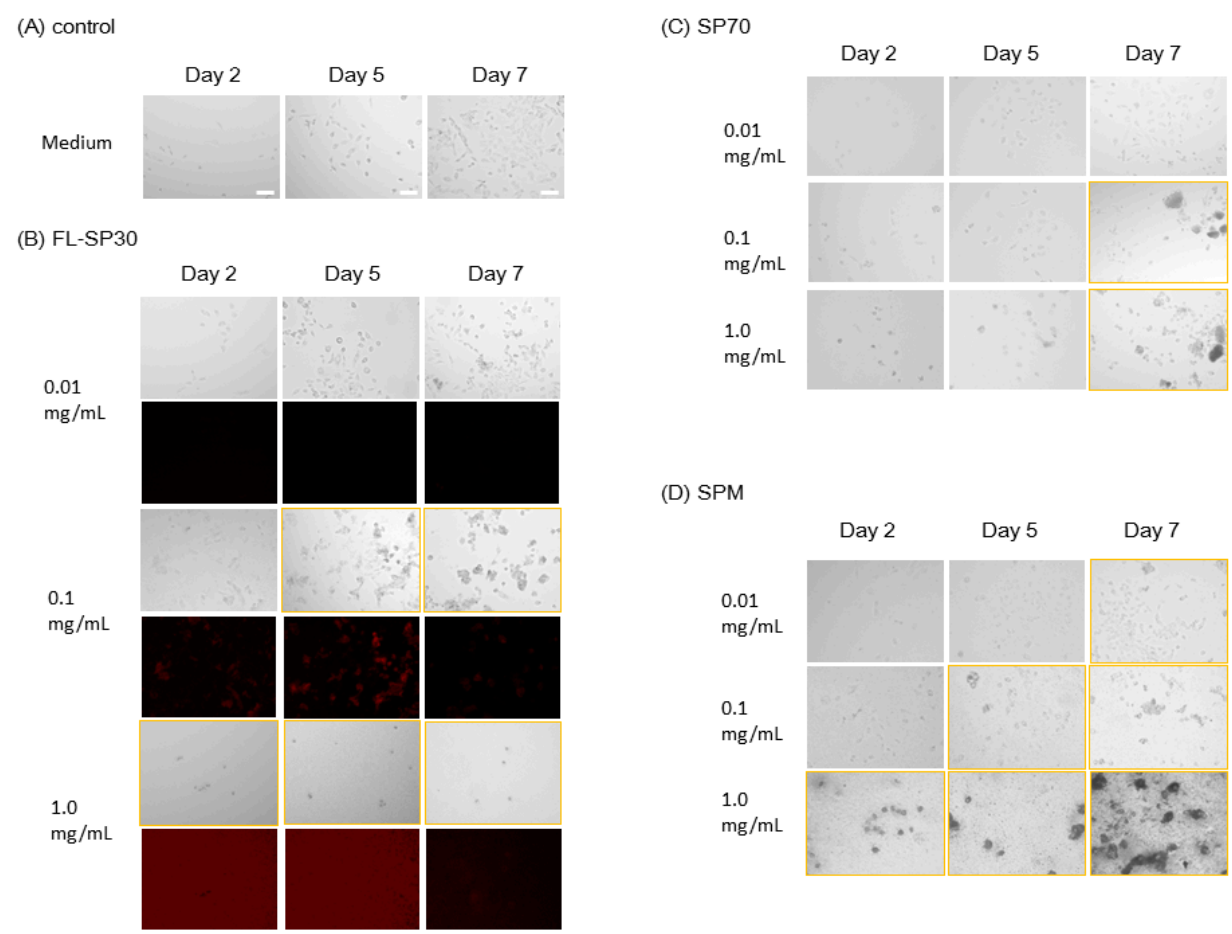
Figure 2. Cont.
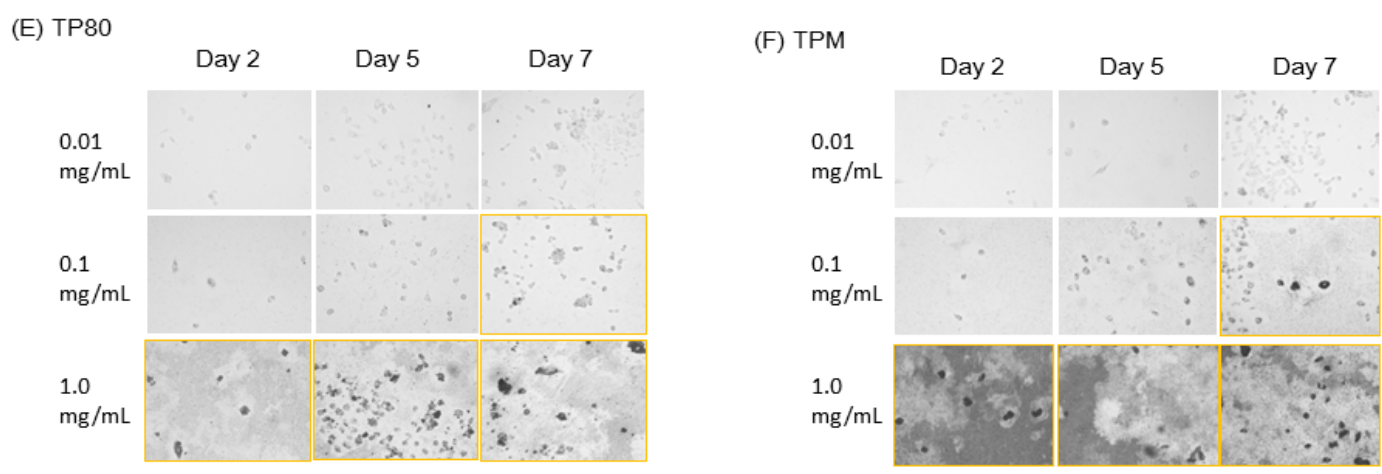

Moreover, the fluorescence images showed that fluorescent 30-nm silica particles (FL-SP30) were attached to or incorporated into hNSCs at $0.1 \mathrm{mg} / \mathrm{mL}$ (Figure 2B). However, few fluorescent particles were detected at $0.01 \mathrm{mg} / \mathrm{mL}$ (Figure 2B). In addition, FL-SP30 particles were also attached to the culture plate at $1.0 \mathrm{mg} / \mathrm{mL}$.

Figure 3. Mitochondrial activity during exposure to particles for 7 days. For avoiding the effects of the interaction between particles and the test reagent/culture plates, the mitochondrial activity was calculated in the subtract absorption, "the absorption of co-cultured well (cell + medium + particles)" - "the absorption of no-cell well (medium + particles)". The results are presented as mean values $(n=3)$. Error bars represent S.D. The differences between control $(0 \mathrm{mg} / \mathrm{mL})$ and particles' treatments were analyzed with Scheffe's F test (\# $p<0.05 ; * p<0.01)$.
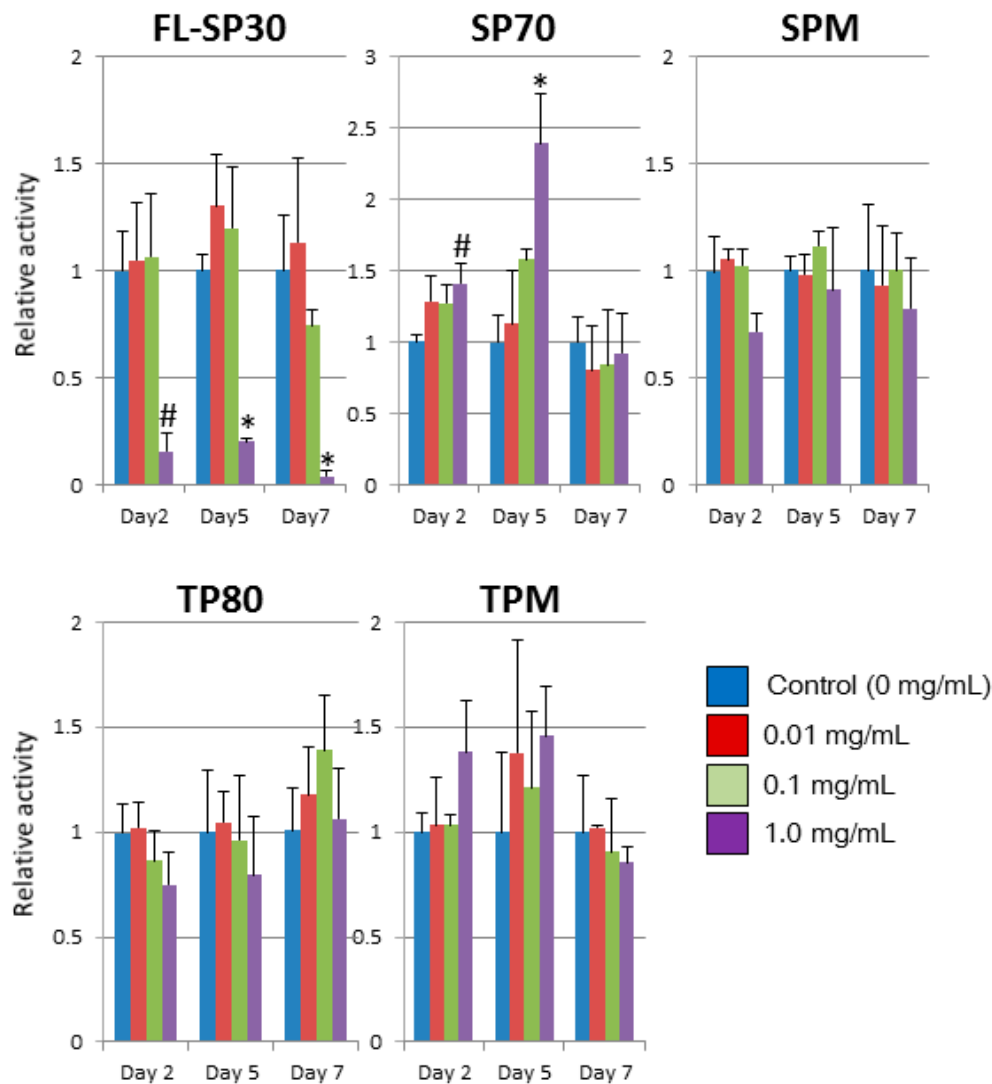
Further, we studied cytotoxic effects of the particles based on mitochondrial activity during 7 days of exposure to particles (Figure 3). The mitochondrial activity of hNSCs was significantly decreased within 2 days by exposure to $1.0 \mathrm{mg} / \mathrm{mL}$ FL-SP30 $(p<0.05)$. The $0.1 \mathrm{mg} / \mathrm{mL}$ FL-SP30 tended to reduce the relative activity to $74.5 \%$ at day 7 . In contrast, other particles did not reduce their relative mitochondrial activities significantly at day 7, although there was variation of mitochondrial activity during the 7 days observed for each particle. For example, the activity of SP70 treatments $(1 \mathrm{mg} / \mathrm{mL})$ significantly increased $(p<0.05)$ and the activity of TPM treatments $(1 \mathrm{mg} / \mathrm{mL})$ tended to increase (n.s.) at days 2 and 5 .

\subsection{Observation of Cellular Membrane Permeation, Mitochondrial Effects, and Effects on Nuclei}

Because only the mitochondrial activities of hNSCs exposed to FL-SP30 were decreased significantly $(p<0.05$ ), we focused on the toxicological effects of $30-\mathrm{nm}$ silica particles. To examine the toxicity in detail, we exposed hNSCs to non-fluorescent $30-\mathrm{nm}$ silica particles (SP30) at several concentrations between $0-250 \mu \mathrm{g} / \mathrm{mL}$ for 7 days and examined the membrane, nuclei, and mitochondrial conditions during this period (Figure 4).

In this experiment, we used SYTOX Green (SG) for nuclear staining to indicate membrane permeability, which is related to viability. At concentrations $\geq 125 \mu \mathrm{g} / \mathrm{mL}$, most cells $(\geq 73 \%)$ were significantly $(p<0.01)$ stained with SG at 7 days (Figure 4A-D). On day 1 , around $81 \%$ cells were stained with SG at $62.5 \mu \mathrm{g} / \mathrm{mL}(p<0.01)$ and $17 \%$ cells were stained at $31.3 \mu \mathrm{g} / \mathrm{mL}(p<0.01)$ (Figure 4A,D). Interestingly, the recovery, as indicated by less staining, was observed at $62.5 \mu \mathrm{g} / \mathrm{mL}$ on days 4 and 7 (Figure 4D). At $0-31.3 \mu \mathrm{g} / \mathrm{mL}$, few cells were stained with SG on days 4 and 7 . From the plots of SG staining ratio during the 7 days, the $\mathrm{IC}_{50}$ on day 1 was between 31.3 and $62.5 \mu \mathrm{g} / \mathrm{mL}$ and the $\mathrm{IC}_{50}$ on days 4 and 7 was between 62.5 and $125 \mu \mathrm{g} / \mathrm{mL}$ (Figure 4D).

To confirm the increase in membrane permeability, we conducted a lactate dehydrogenase (LDH) assay. Although no statistically significant difference was found among the SP30 treated groups with Scheffe's F test, LDH release, which suggested cellular membrane damages, increased at SP30 concentrations $\geq 250 \mu \mathrm{g} / \mathrm{mL}$ on day 1 (Figure $4 \mathrm{G}$ ).

On the other hand, the fluorescence intensity of MitoRed, which indicates the electrical potential of mitochondrial activity, showed no significant difference (Figure 4E).

Furthermore, fluorescent images obtained using the nuclear staining reagent Hoechst 33342, which indicates apoptosis at high staining intensities, showed a concentration-dependent decrease between 31.3 and $125 \mu \mathrm{g} / \mathrm{mL}$ (Figure $4 \mathrm{~F}$ ). At $250 \mu \mathrm{g} / \mathrm{mL}$, the fluorescence intensity exhibited a tendency to increase at day 1 and 4, whereas it decreased at day 7 (Figure 4F). 
Figure 4. Representative images of nuclei (SYTOX Green and Hoechst) and mitochondria (Mitored) of hNSCs exposed to SP30 (0-250 $\mu \mathrm{g} / \mathrm{mL}$ for 7 days), (A) Day 1; (B) day 4; and (C) day 7. Observation was conducted with High Content Imaging System Operetta. From the observation images, around 500-4200 cells were analyzed with the Operetta system in each condition $(n=3)$ (D-F). (D) Ratio of cells stained with SYTOX Green; (E) Average intensity of MitoRed staining; (F) Average intensity of Hoechst 33342 staining; (G) Lactate dehydrogenase $(\mathrm{LDH})$ assay result at day $1(n=3)$. Error bars represent S.D. The differences between control $(0 \mu \mathrm{g} / \mathrm{mL})$ and SP30-treatments were analyzed with Scheffe's F test (\#p<0.05; ${ }^{*} p<0.01$ ) in each day (D-G). Scale bar (white) indicates $100 \mu \mathrm{m}$.

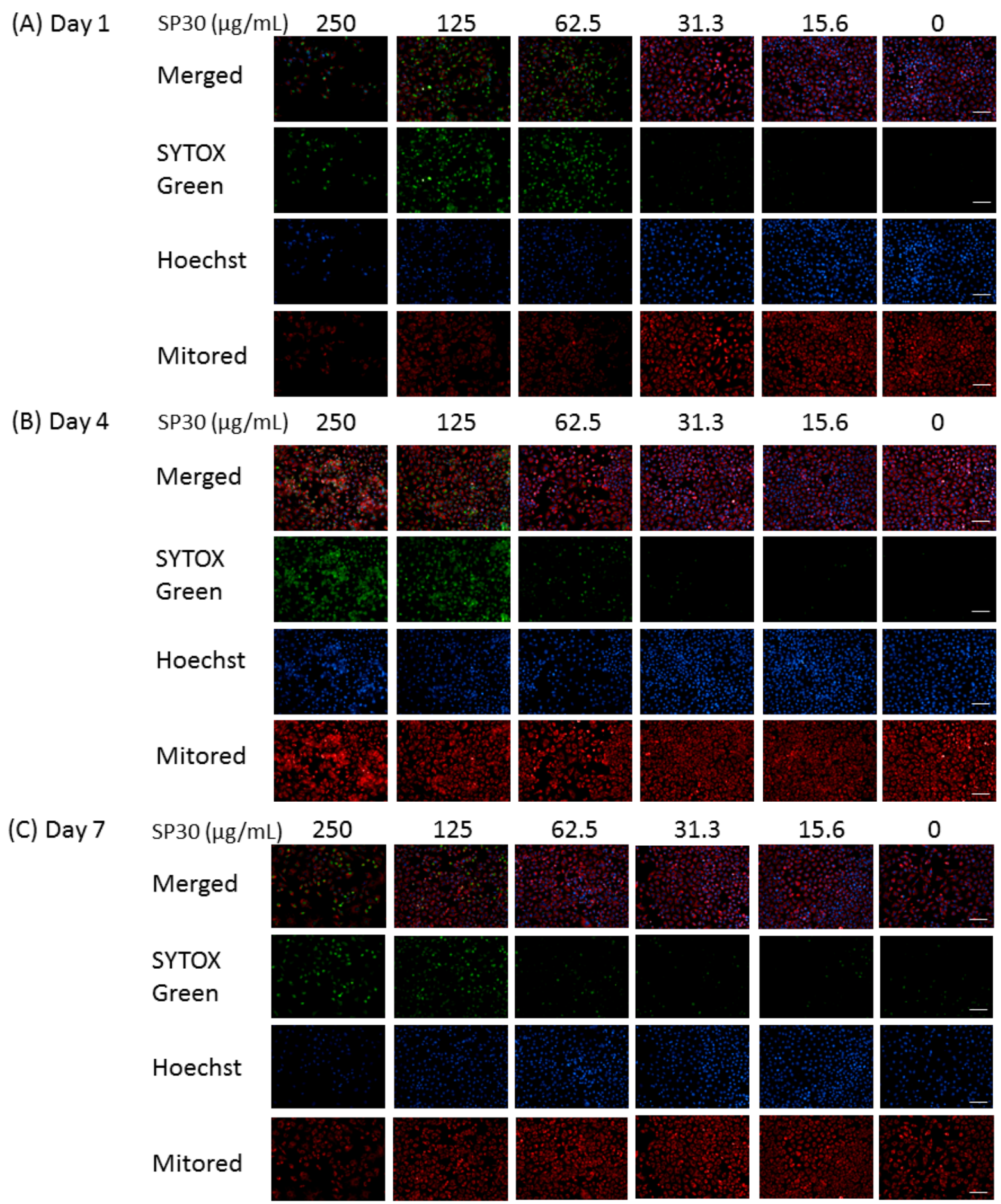


Figure 4. Cont.

(D)

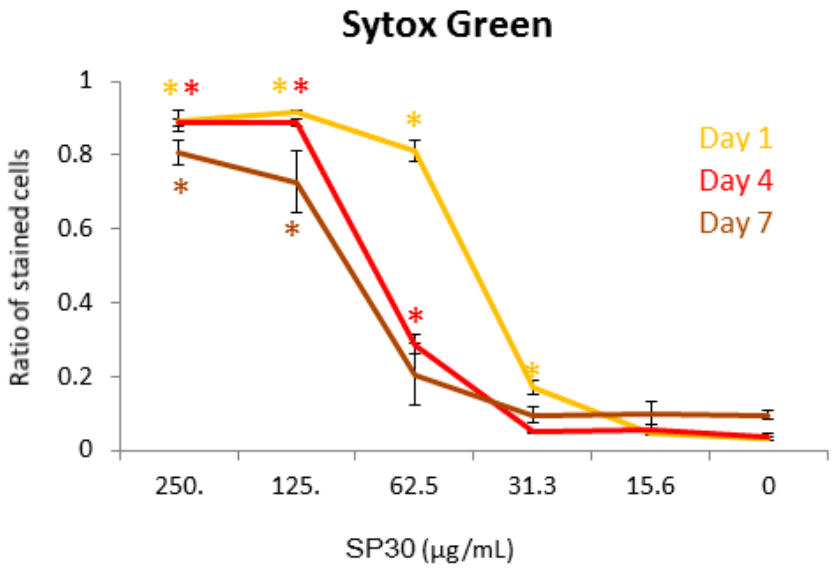

(F)

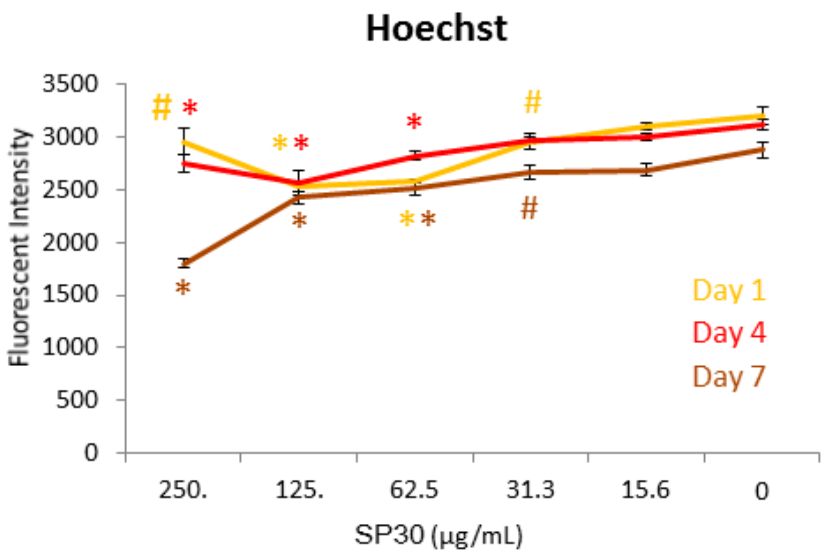

$(\mathrm{E})$

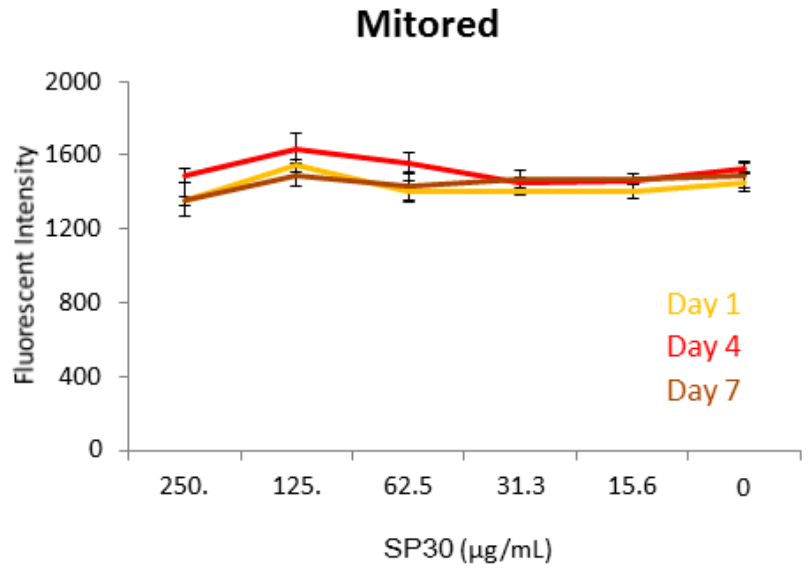

(G)

LDH Assay (Day 1)

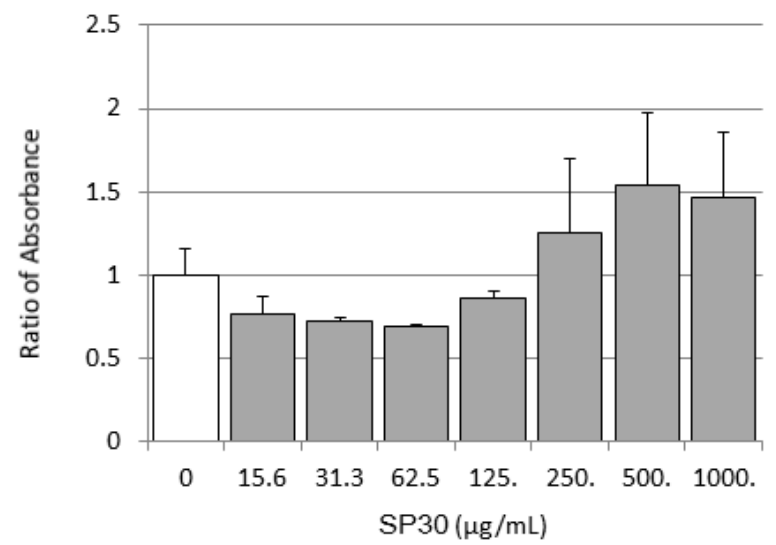

\subsection{Gene Expression of hNSCs Exposed to Particles}

Because we found increased membrane permeability of SP30 at the concentrations $\geq 62.5 \mu \mathrm{g} / \mathrm{mL}$ at day 1 (Figure 4D), we examined the differentiation activity of hNSCs exposed to $0.1 \mathrm{mg} / \mathrm{mL}$. Figure 5A shows the expression profile of genes related to hNSCs differentiation after 24-h exposure of hNSCs to particles at $0.1 \mathrm{mg} / \mathrm{mL}$. We observed the increased expression of Nestin (stem cell marker) and neurofilament heavy polypeptide ( $N-F H$; neuron marker) in hNSCs after exposure with all the particles (Figure 5A). Moreover, FL-SP30 and SPM exposure increased the expression of glial fibrillary acidic protein (GFAP; astrocyte marker).

Interestingly, the expression of the high mobility group AT-hook 1 (HMGA1) gene, which is required for neuronal differentiation during the fetal period [34], was decreased in hNSCs exposed to FL-SP30, which was a different effect than that from other particles (Figure 5B). Focused on FL-SP30 effects, the expression of the HMGA1 gene was significantly reduced $(p<0.05)$, while the gene expressions of $H M G A 2$, which has similar activity to $H M G A 1$, and DNA methyltransferase 1 (DNMT1), a gene with increased expression in senescent cells, were not significantly affected (Figure 5C). 
Figure 5. Effects of $0.1 \mathrm{mg} / \mathrm{mL}$ particles on gene expression of brain cell markers. (A) PCR analyses for differentiation markers (representative data, $n=2)$; (B) Real-time PCR analyses for HMGA1 expression $(n=2)$; (C) Effects of FL-SP30 on cellular activity markers in hNSCs $(n=3)$. The differences between Control and FL-SP30 treatments were analyzed by two-sided Student's $t$ test $(p<0.05)(\mathbf{C})$. Error bars represent S.D. The n.s. indicates not significantly different from the Control $(p<0.05)$.

(A)

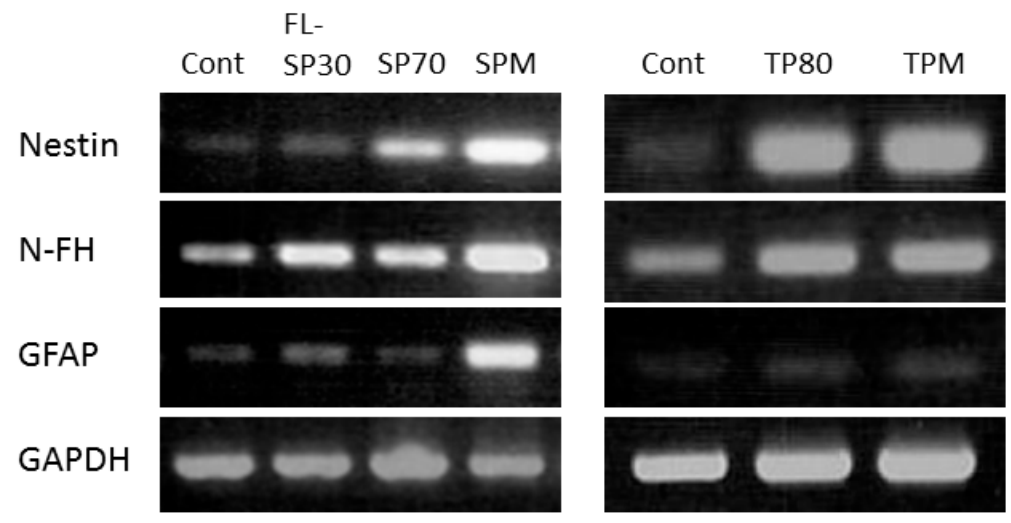

(B)

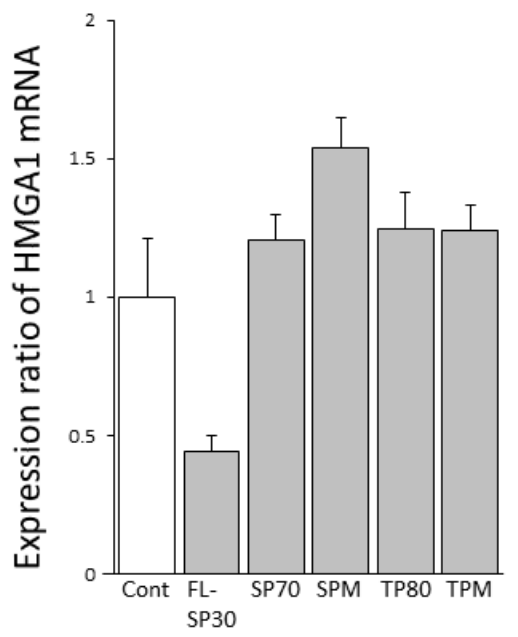

(C)

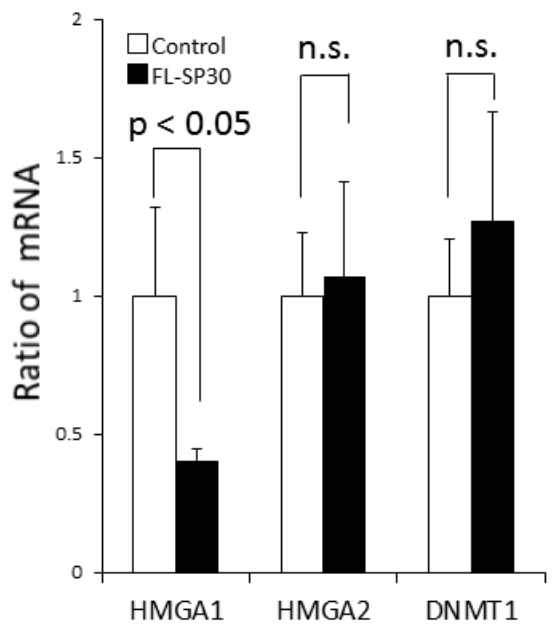

\section{Discussion}

This study demonstrated that all five particles possessed the ability to affect hNSC morphology at concentrations $\geq 0.1 \mathrm{mg} / \mathrm{mL}$ (Figure 2). In addition, we found that $30-\mathrm{nm}$ silica particles significantly affected the mitochondrial activity of hNSCs at $1.0 \mathrm{mg} / \mathrm{mL}$ (Figure 3) and membrane permeability at concentrations $\geq 62.5 \mu \mathrm{g} / \mathrm{mL}$ (Figure 4).

These toxicological concentrations may not be realistic in the brain at single exposure because another in vivo study suggested that the ratio of quantum dots accumulation in the brain was approximately $0.1 \%$ of the dose [23]. However, continuous or long-term exposure may increase the concentration in the brain. Therefore, these thresholds may indicate the potential toxicity of accumulated particles for long-term usage or continuous exposure. Moreover, these concentrations will provide a 
reference for the maximum particles dose for NSCs and will be useful in the fields of occupational and consumer health until the long-term influences in vivo at lower concentration are revealed.

Toxicological effects were detected at 0.1 and $1.0 \mathrm{mg} / \mathrm{mL}$, regardless of the main particle sizes or materials (Figure 2). Moreover, the concentration that induced cellular aggregation appeared to be different by the types of particles. As for the relevance of particles sizes to up-taken particles, Sakai et al. showed that the fluorescent polystyrene nanoparticles (22 and $100 \mathrm{~nm}$ ) were taken up in rat pheochromocytoma (PC12) cells more than microparticles $(1000 \mathrm{~nm})$ both in particle number and weight [37]. Additionally, they showed that all the particles decreased cellular viability (mitochondrial activity) at $10 \%$ concentration of particles for $24-\mathrm{h}$ culture and then 22 -nm particles ( $0 \%$ of viability) was more cytotoxic than other $100 \mathrm{~nm}(73 \%)$ and $1000 \mathrm{~nm} \mathrm{(54 \% )} \mathrm{particles} \mathrm{[37].} \mathrm{Our} \mathrm{data} \mathrm{also} \mathrm{showed}$ that all the nano and microparticles affected cellular morphology $\geq 0.1 \mathrm{mg} / \mathrm{mL}$ within 7 days (Figure 2) and 30-nm silica particles decreased the mitochondrial activity more than other particles (Figure 3). With regard to the toxicity of nano-silica particles $(21,48$, and $86 \mathrm{~nm})$, Ye et al. reported that the cytotoxicity of particles depended on the size, concentration, and time in the L-02 human hepatic cell line [38]. These results led to the hypothesis that (1) the cytotoxicity mechanism of particles may be different in the particles' sizes, especially nanoparticles or microparticles; and (2) around 21-30 nm particles may be more cytotoxic than other larger nanoparticles.

How did the 30-nm silica particles affect hNSCs? One important factor was membrane damage by 30-nm silica particles (Figure 4). Recent toxicological studies on silica particles have suggested that the ROS production due to silica particles contributes to the toxicological effects. For example, Kim et al. reported that several silica particles smaller than $20 \mathrm{~nm}$ increased ROS production dose-dependently in the SH-SY5Y human neural cell line [39]. Park et al. indicated that 20-nm silica particles caused greater cell damage and ROS production than 100-nm particles in the HaCaT human keratinocyte cell line [40]. Because ROS-related lipid peroxidation has also been reported using nano-silica particles [38], ROS generated by 30-nm silica particles used in this study may induce membrane damages in NSCs. Actually, although we tried to detect ROS with 2',7'-dichlorofluorescin diacetate, we have not yet obtained the evidence of ROS generation in hNSCs by $30-\mathrm{nm}$ silica particles (data not shown). In future studies, the mechanism should be investigated.

We also investigated osmotic pressure as another mechanism underlying membrane damage. However, osmotic pressure may not be relevant to membrane permeability in the present study, because the pressure of the solution was not affected significantly (around detection limit: $\pm 0.001 \mathrm{mOsm} / \mathrm{kg}$ ) at the SP30 concentration of $1.0 \mathrm{mg} / \mathrm{mL}$ or less (data not shown).

Observations of nuclei and mitochondria during exposure to SP30 showed a significant increased rate of SG staining, indicating disrupted cell membranes and necrosis (Figure 4). These results also revealed that the threshold concentration for acute membrane permeation during $24 \mathrm{~h}$ was $62.5 \mu \mathrm{g} / \mathrm{mL}$. In addition, from the observations of FL-SP30, we detected attachment or incorporated particles around hNSCs at $0.1 \mathrm{mg} / \mathrm{mL}$ but not at $0.01 \mathrm{mg} / \mathrm{mL}$ (Figure 2B). These data also supported an acute increase in membrane permeability above the threshold concentration and did not conflict the report by Song et al., which showed that proliferations and viabilities of hNSCs were not affected by the co-culture of several nanoparticles at $25 \mu \mathrm{g} / \mathrm{mL}$ for $24 \mathrm{~h}$ [35]. Interestingly, a repair mechanism or resistance to membrane permeation was also suggested, because the $\mathrm{SG}$ staining ratio at $62.5 \mu \mathrm{g} / \mathrm{mL}$ decreased at days 4 and 7 (Figure 4D). 
Our findings on the gene expression of differentiation markers suggest that exposure to all the particles in this study increased Nestin and $\mathrm{N}-\mathrm{FH}$ expression (Figure 5A). Moreover, we found an increase in the expression of GFAP after exposure to FL-SP30 and SPM at $0.1 \mathrm{mg} / \mathrm{mL}$ (Figure 5A). These results suggested that exposure to particles (irrespective of their size) may lead not only to self-renewal but also to promotion of neural differentiation spontaneously, maybe due to the toxicological effects. Furthermore, FL-SP30 and SPM at $0.1 \mathrm{mg} / \mathrm{mL}$ have the potential to lead to astrocyte differentiation of NSCs. Similar to our results, another study showed that the mouse NSC cell line $\mathrm{C} 17.2$, exposed to $0.15 \mathrm{mg} / \mathrm{mL}$ titanium oxide nanoparticles coated with $\mathrm{SiO}_{2}(80-100 \mathrm{~nm}$ in diameter) for 7 days, was induced to differentiate into neurons [41]. Therefore, exposure to silica or titanium particles may affect the differentiation of NSCs.

Finally, we found that exposure to FL-SP30 decreased the gene expression of HMGA1 in hNSCs slightly (Figure 5C), which is required for neural development [34]. This result suggested that FL-SP30 at $0.1 \mathrm{mg} / \mathrm{mL}$ may decrease the neurogenesis of hNSCs. On the other hand, we have found the increase of $\mathrm{NF}-\mathrm{H}$ gene expression, neuronal marker (Figure 5A). Therefore, in a future study, the activity of neurons or the ratio of neurons differentiated from hNSCs exposed to the 30-nm or smaller than 100-nm silica particles should be examined. Notably, our previous study showed the same FL-SP30 (used in this report) indicated a slight penetration ability into brain area in the blood brain barrier model in vitro [30]. Moreover, other researchers showed silica particles smaller than $100 \mathrm{~nm}$ crossed the blood brain barrier [42] and placenta [29] in vivo.

\section{Experimental Section}

\subsection{Particles}

Silicon dioxide, $70 \mathrm{~nm}$ (Wako Pure Chemical Industries, Osaka, Japan), silicon dioxide, -325 mesh (Sigma-Aldrich, St. Louis, MO, USA), sicastar, non-coating, $30 \mathrm{~nm}$ (Micromod Partikeltechnologie $\mathrm{GmbH}$, Rostock, Germany), and sicastar-redF, non-coating, 30 (Micromod Partikeltechnologie GmbH) were used as silica particles, namely SP70, SPM, SP30 and FL-SP30, respectively. Titanium (IV) oxide, $80 \mathrm{~nm}$ (Wako Pure Chemical Industries, Osaka, Japan), Titanium (IV) oxide, anatase, powder, -325 mesh (Aldrich, St. Louis, MO, USA) were used as titanium oxide particles, namely TP80 and TPM, respectively.

Since the $30 \mathrm{~nm}$ silica nanoparticles was dispersed in an aqueous solution, we centrifuged the solution at 65,000 rpm for $8 \mathrm{~h}$ at room temperature (Himac CP80MX, Hitachi, Tokyo, Japan). The obtained precipitate was further dried by a centrifugal evaporator (CVE200D, Tokyo Rika Kikai, Tokyo, Japan) for SEM measurement. For investigation of physical properties about dispersed particles in Milli-Q water (Merck Millipore, Billerica, MA, USA) (Table 1), we measured size in DLS, PDI, and zeta-potential, two (zeta potential of SP30) or three times (other measurement) with Zetasizer Nano ZS (Malvern Instruments, Worcestershire, UK) in default measurement mode. We showed average data in the Table 1. After experiments, we measured the $\mathrm{pH}$ of Milli-Q with $\mathrm{pH}$ indictor paper (Whatmann $\mathrm{pH}$ 1-11 indicator paper, GE Healthcare UK Ltd., Buckinghamshire, UK), which indicated pH 5. Additionally, we observed the particles with ultra-high resolution scanning electron microscope SU8000 (Hitachi, Tokyo, Japan). 


\subsection{Cell Culture and Morphology Observation of Human Neural Stem Cell Line}

HB1.F3 human neural stem cell line described in references [43-45] was cultured in high-glucose DMEM (Life Technologies, Carlsbad, CA, USA) with 10\% fetal bovine serum and penicillin streptomycin, in culture plates under the condition humidified $5 \% \mathrm{CO}_{2}$ at $37^{\circ} \mathrm{C}$. Culture plates, Costar 24 Well Clear TC-Treated Multiple Well Plates, Individually Wrapped, Sterile (Corning Incorporated, Corning, NY, USA), Corning 96 Well Clear Flat Bottom TC-Treated Microplate, Individually Wrapped, with Low Evaporation Lid, Sterile (Corning Incorporated, Corning, NY, USA), or ViewPlate-96 Black, Optically Clear Bottom, Tissue Culture Treated, Sterile, 96-Well with Lid (PerkinElmer, Waltham, MA, USA) were used for the hNSC cultures and particles treatments. All the particles were added into the culture medium at the indicated concentrations, quickly after dispersed in Milli-Q water.

For morphology observation, $4 \times 10^{4}$ hNSCs were added into each well of the 24 -well plate (Corning Incorporated, Corning, NY, USA). Forty-eight hours after seeding the cells, each well was treated with the indicated doses of particles for 48-168 h (Day 2: 48 h; Day 5: 120 h; Day 7: $168 \mathrm{~h}$ in Figure 2), with particles in concentration of $0,0.01,0.1$, or $1.0 \mathrm{mg} / \mathrm{mL}$. Each experiment was conducted two times independently. The co-cultured hNSCs in Figure 2 were observed with BZ-9000 (Keyence, Osaka, Japan) after trypan blue staining. In the fluorescent images in Figure $2 \mathrm{~B}$, brightness of the fluorescent images at $1.0 \mathrm{mg} / \mathrm{mL}$ was reduced by 50\% with PowerPoint 2013 (Microsoft, Redmond, WA, USA) for visibility, since 30-nm fluorescent silica particles attached to the basement of the plate. Background brightness of other non-fluorescent wells was adjusted using PowerPoint for comparing colors.

\subsection{Mitochondrial Activity Assay}

The effect of particles on the hNSC mitochondrial activity was measured using the Cell Counting Kit-8 (CCK-8, Dojindo Molecular Technologies, Kumamoto, Japan) as previously described [16,37,46]. Briefly, $1 \times 10^{4} \mathrm{hNSC}$ were added into each well of the 96-well plate above (Corning Incorporated, Corning, NY, USA). Forty-eight hours after seeding the cells, each well was treated with indicated doses of particles for 48-168 h (Day 2: 48 h; Day 5: 120 h; Day 7: $168 \mathrm{~h}$ in Figure 3), with particles in concentration of $0,0.01,0.1$, or $1.0 \mathrm{mg} / \mathrm{mL}$. Each experiment was conducted three times independently. Then the CCK-8 solution was added to each well. After cells were incubated for another 30-60 min, the absorbance at $450 \mathrm{~nm}$ was measured using a microplate reader (680XR, Bio-Rad, Hercules, CA, USA). The mitochondrial activity was calculated in the subtracted absorption, "the absorption of co-cultured well (cell + medium + particles)"- "the absorption of no-cell well (medium + particles)", because some particles, themselves, may have the potential to increase the absorption due to their reducing potential and attachment of plates. Each experiment was done in triplicates. The differences between control $(0 \mathrm{mg} / \mathrm{mL})$ and particles' treatments were analyzed with Scheffe's F test (\# $p<0.05 ; * p<0.01$ ) (Figure 3).

\subsection{Observation of Cytotoxic Effects with Nuclear and Mitochondria Staining}

hNSC $\left(1 \times 10^{4}\right.$ cells) were added to each well of the 96-well plate mentioned above (PerkinElmer, Waltham, MA, USA). From $48 \mathrm{~h}$ after seeding the cells, each well was treated with $0-250 \mu \mathrm{g} / \mathrm{mL}$ of SP30 for 24-168 h (Day 1: 24 h; Day 4: 96 h; Day 7: 168 h) in Figure 4. SYTOX Green 11 Nucleic 
Acid Stain (Life Technologies, Carlsbad, CA, USA) as lower membrane permeability reagent, and Hoechst 33342 solution (Dojindo Molecular Technologies, Kumamoto, Japan) as higher membrane permeability reagent were used for nucleic acid staining. Mitochondria were stained with MitoRed (Dojindo Molecular Technologies, Kumamoto, Japan). After fixation, these stained hNSC were observed with High Content Imaging System Operetta (PerkinElmer, Waltham, MA, USA). Each particles treatments were conducted three times independently and whole samples were observed at one day with the Operetta. The differences between control $(0 \mu \mathrm{g} / \mathrm{mL})$ and SP30-treatments $(0-250 \mu \mathrm{g} / \mathrm{mL})$ were analyzed with Scheffe's F test (\# $\left.p<0.05 ;{ }^{*} p<0.01\right)$ in each day (Figure 4D-F).

\subsection{Lactate Dehydrogenase (LDH) Assay}

For the measurement of LDH release from hNSC cells exposed to the indicated SP30 for $24 \mathrm{~h}$ (three independent experiments), we used an LDH Cytotoxicity Detection Kit (Takara Bio, Shiga, Japan) as an indicator for plasma membrane leakage as described in our previous paper [16]. The $490 \mathrm{~nm}$ absorption of formazans as an indicator of $\mathrm{LDH}$ releases were measured with a plate reader. The differences between control $(0 \mu \mathrm{g} / \mathrm{mL})$ and SP30-treatments $(0-1000 \mu \mathrm{g} / \mathrm{mL})$ were analyzed with Scheffe's F test (\# $p<0.05 ; * p<0.01)$ (Figure 4F).

\subsection{PCR and Real-Time PCR Analyses}

We performed PCR analyses and real-time PCR (RT-PCR) analyses of hNSCs to identify the expressed gene after $24 \mathrm{~h}$-exposure of a $0.1 \mathrm{mg} / \mathrm{mL}$ of particles solution. Total RNAs were prepared from the hNSCs which were treated with particles in $0.1 \mu \mathrm{g} / \mathrm{mL}$ ( 24 well plate) for $24 \mathrm{~h}$, using ISOGEN II (Nippongene, Tokyo, Japan). Each experiment was conducted two or three times independently. These RNAs were reverse-transcribed with ReverTra Ace qPCR RT Master Mix with gDNA Remover (Toyobo, Osaka, Japan).

PCR assays were conducted with Quick Taq HS DyeMix (Toyobo, Osaka, Japan) reagent and the amplified samples were loaded to 1.5\% agarose gels (Agarose S, Nippongene, Tokyo, Japan). RT-PCR analyses were conducted with FastStart Universal SYBR Green Master (ROX) reagent (Roche, Basel, Switzerland) using the 7300 Real Time PCR System (Applied Biosystems, Carlsbad, CA, USA).

For PCR and RT-PCR primers, Perfect Real Time Primer (Takara Bio, Shiga, Japan) were used for amplifications as below, HA042877 for Nestin, HA151016 for neurofilament, heavy polypeptide $(N-F H)$, HA157438 for glial fibrillary acidic protein $(G F A P)$, HA180245 for high mobility group AT-hook 1 (HMGA1), HA08633 for high mobility group AT-hook 2 (HMGA2), and HA126052 for DNA (cytosine-5-)-methyltransferase 1 (DNMT1). For glyceraldehyde-3-phosphate dehydrogenase $(G A P D H)$ amplification, Perfect Real Time Primer HA067812 and custom primer sets synthesized in Greinar Japan, Tokyo, Japan (forward 5'-CATGACCACAGTCCATGCCATCACT-3', reverse 5'-TGAGGTCCACCACCCTGTTGCTGTA-3' [45]) were used in RT-PCR analyses and PCR analyses, respectively. For the data analysis, the differences between control and FL-SP30 treatments were analyzed by two-sided Student's $t$ test (Figure 5C). 


\subsection{Statistical Analyses}

Statistical analyses mentioned above were performed with Microsoft Office Excel 2007 (Microsoft, Redmond, WA, USA) and the add-in software Statcel 3 (OMS publishing Inc., Saitama, Japan).

\section{Conclusions}

This study demonstrated that all the silica and titanium oxide particles both smaller and greater than $100 \mathrm{~nm}$ (1) had the ability to affect hNSCs morphology at the concentration of $\geq 0.1 \mathrm{mg} / \mathrm{mL}$ during 7 days of culture and (2) affected the gene expression of differentiation markers at a concentration of $0.1 \mathrm{mg} / \mathrm{mL}$. Although these toxicological concentrations were higher than the expected concentrations in the brain resulting from the injection/exposure in vivo experiments in a short period, these thresholds may indicate the potential toxicity of accumulated particles for long-term usage or continuous exposure.

\section{Acknowledgments}

This study was supported by Health and Labor Sciences Research Grants from the Ministry of Health, Labor and Welfare of Japan (H22-chemical-young-009) and partially supported by The Japan Science Society (Sasakawa Grants for Science Fellows). We appreciate Masashi Isogai (PerkinElmer Japan) and Masaki Shimura (PerkinElmer Japan) for useful advice and performing the nucleic acids and mitochondrial observation with the High Content Imaging System Operetta. We also thank Professor Toya Ohashi (The Jikei University School of Medicine) for coordinating the cell line usage.

\section{Author Contributions}

Study conception and design: Kouki Fujioka, Sanshiro Hanada, Yuriko Inoue, Kenji Hirakuri, Fumihide Kanaya, Keiichi Ikeda, Kenji Yamamoto, Seung U. Kim, and Yoshinobu Manome; Acquisition of data: Kouki Fujioka, Sanshiro Hanada, Keisuke Sato, Kenji Hirakuri, and Ritsuko Usui; Analysis and interpretation of data; Kouki Fujioka, Sanshiro Hanada, Keisuke Sato, and Kouichi Shiraishi; Drafting of manuscript: Kouki Fujioka; Revision: Kouki Fujioka, Sanshiro Hanada, Yuriko Inoue, Keisuke Sato, Kouichi Shiraishi, Fumihide Kanaya, and Seung U. Kim.

\section{Conflicts of Interest}

The authors declare no conflict of interest.

\section{References}

1. Kaur, I.P.; Agrawal, R. Nanotechnology: A new paradigm in cosmeceuticals. Recent Pat. Drug Deliv. Formul. 2007, 1, 171-182.

2. Papakostas, D.; Rancan, F.; Sterry, W.; Blume-Peytavi, U.; Vogt, A. Nanoparticles in dermatology. Arch. Dermatol. Res. 2011, 303, 533-550.

3. Dekkers, S.; Krystek, P.; Peters, R.J.; Lankveld, D.P.; Bokkers, B.G.; van Hoeven-Arentzen, P.H.; Bouwmeester, H.; Oomen, A.G. Presence and risks of nanosilica in food products. Nanotoxicology 2011, 5, 393-405. 
4. Weir, A.; Westerhoff, P.; Fabricius, L.; Hristovski, K.; von Goetz, N. Titanium dioxide nanoparticles in food and personal care products. Environ. Sci. Technol. 2012, 46, 2242-2250.

5. Matsuzaki, H.; Maeda, M.; Lee, S.; Nishimura, Y.; Kumagai-Takei, N.; Hayashi, H.; Yamamoto, S.; Hatayama, T.; Kojima, Y.; Tabata, R.; et al. Asbestos-induced cellular and molecular alteration of immunocompetent cells and their relationship with chronic inflammation and carcinogenesis. J. Biomed. Biotechnol. 2012, 2012, 492608.

6. Myers, R. Asbestos-related pleural disease. Curr. Opin. Pulm. Med. 2012, 18, 377-381.

7. Kanarek, M.S. Mesothelioma from chrysotile asbestos: Update. Ann. Epidemiol. 2011, 21, 688-697.

8. Auffan, M.; Rose, J.; Bottero, J.Y.; Lowry, G.V.; Jolivet, J.P.; Wiesner, M.R. Towards a definition of inorganic nanoparticles from an environmental, health and safety perspective. Nat. Nanotechnol. 2009, 4, 634-641.

9. Han, X.; Corson, N.; Wade-Mercer, P.; Gelein, R.; Jiang, J.; Sahu, M.; Biswas, P.; Finkelstein, J.N.; Elder, A.; Oberdorster, G. Assessing the relevance of in vitro studies in nanotoxicology by examining correlations between in vitro and in vivo data. Toxicology 2012, 297, 1-9.

10. Johnston, H.J.; Hutchison, G.R.; Christensen, F.M.; Peters, S.; Hankin, S.; Aschberger, K.; Stone, V. A critical review of the biological mechanisms underlying the in vivo and in vitro toxicity of carbon nanotubes: The contribution of physico-chemical characteristics. Nanotoxicology 2010, 4, 207-246.

11. Oberdorster, G.; Oberdorster, E.; Oberdorster, J. Nanotoxicology: An emerging discipline evolving from studies of ultrafine particles. Environ. Health Perspect. 2005, 113, 823-839.

12. Li, Y.; Zhang, Y.; Yan, B. Nanotoxicity overview: Nano-threat to susceptible populations. Int. J. Mol. Sci. 2014, 15, 3671-397.

13. Hoshino, A.; Fujioka, K.; Oku, T.; Suga, M.; Sasaki, Y.F.; Ohta, T.; Yasuhara, M.; Suzuki, K.; Yamamoto, K. Physicochemical properties and cellular toxicity of nanocrystal quantum dots depend on their surface modification. Nano Lett. 2004, 4, 2163-2169.

14. Iavicoli, I.; Leso, V.; Fontana, L.; Bergamaschi, A. Toxicological effects of titanium dioxide nanoparticles: A review of in vitro mammalian studies. Eur. Rev. Med. Pharmacol. Sci. 2011, 15, 481-508.

15. Jaeger, A.; Weiss, D.G.; Jonas, L.; Kriehuber, R. Oxidative stress-induced cytotoxic and genotoxic effects of nano-sized titanium dioxide particles in human HaCaT keratinocytes. Toxicology 2012 , 296, 27-36.

16. Fujioka, K.; Hiruoka, M.; Sato, K.; Manabe, N.; Miyasaka, R.; Hanada, S.; Hoshino, A.; Tilley, R.D.; Manome, Y.; Hirakuri, K.; et al. Luminescent passive-oxidized silicon quantum dots as biological staining labels and their cytotoxicity effects at high concentration. Nanotechnology 2008, 19, 415102.

17. Yoshida, T.; Yoshikawa, T.; Nabeshi, H.; Matsuyama, K.; Hirai, T.; Akase, T.; Yoshioka, Y.; Itoh, N.; Tsutsumi, Y. Amorphous nanosilica particles induce ROS generation in Langerhans cells. Pharmazie 2012, 67, 740-741.

18. Singh, R.P.; Ramarao, P. Cellular uptake, intracellular trafficking and cytotoxicity of silver nanoparticles. Toxicol. Lett. 2012, 213, 249-259.

19. Snyder-Talkington, B.N.; Qian, Y.; Castranova, V.; Guo, N.L. New perspectives for in vitro risk assessment of multiwalled carbon nanotubes: Application of coculture and bioinformatics. J. Toxicol. Environ. Health B Crit. Rev. 2012, 15, 468-492. 
20. Tang, M.; Zhang, T.; Xue, Y.; Wang, S.; Huang, M.; Yang, Y.; Lu, M.; Lei, H.; Kong, L.; Wang, Y.; et al. Metabonomic studies of biochemical changes in the serum of rats by intratracheally instilled $\mathrm{TiO}_{2}$ nanoparticles. J. Nanosci. Nanotechnol. 2011, 11, 3065-3074.

21. Park, E.J.; Bae, E.; Yi, J.; Kim, Y.; Choi, K.; Lee, S.H.; Yoon, J.; Lee, B.C.; Park, K. Repeated-dose toxicity and inflammatory responses in mice by oral administration of silver nanoparticles. Environ. Toxicol. Pharmacol. 2010, 30, 162-168.

22. Praetner, M.; Rehberg, M.; Bihari, P.; Lerchenberger, M.; Uhl, B.; Holzer, M.; Eichhorn, M.E.; Furst, R.; Perisic, T.; Reichel, C.A.; et al. The contribution of the capillary endothelium to blood clearance and tissue deposition of anionic quantum dots in vivo. Biomaterials 2010, 31, 6692-6700.

23. Kato, S.; Itoh, K.; Yaoi, T.; Tozawa, T.; Yoshikawa, Y.; Yasui, H.; Kanamura, N.; Hoshino, A.; Manabe, N.; Yamamoto, K.; et al. Organ distribution of quantum dots after intraperitoneal administration, with special reference to area-specific distribution in the brain. Nanotechnology 2010, 21, 335103.

24. Ye, L.; Yong, K.T.; Liu, L.; Roy, I.; Hu, R.; Zhu, J.; Cai, H.; Law, W.C.; Liu, J.; Wang, K.; et al. A pilot study in non-human primates shows no adverse response to intravenous injection of quantum dots. Nat. Nanotechnol. 2012, 7, 453-458.

25. Wang, J.; Liu, Y.; Jiao, F.; Lao, F.; Li, W.; Gu, Y.; Li, Y.; Ge, C.; Zhou, G.; Li, B.; et al. Time-dependent translocation and potential impairment on central nervous system by intranasally instilled $\mathrm{TiO}_{2}$ nanoparticles. Toxicology 2008, 254, 82-90.

26. Oberdorster, G.; Sharp, Z.; Atudorei, V.; Elder, A.; Gelein, R.; Kreyling, W.; Cox, C. Translocation of inhaled ultrafine particles to the brain. Inhal. Toxicol. 2004, 16, 437-445.

27. Oberdorster, G.; Elder, A.; Rinderknecht, A. Nanoparticles and the brain: Cause for concern? J. Nanosci. Nanotechnol. 2009, 9, 4996-5007.

28. Dan, M.; Tseng, M.T.; Wu, P.; Unrine, J.M.; Grulke, E.A.; Yokel, R.A. Brain microvascular endothelial cell association and distribution of a $5 \mathrm{~nm}$ ceria engineered nanomaterial. Int. J. Nanomed. 2012, 7, 4023-4036.

29. Yamashita, K.; Yoshioka, Y.; Higashisaka, K.; Mimura, K.; Morishita, Y.; Nozaki, M.; Yoshida, T.; Ogura, T.; Nabeshi, H.; Nagano, K.; et al. Silica and titanium dioxide nanoparticles cause pregnancy complications in mice. Nat. Nanotechnol. 2011, 6, 321-328.

30. Hanada, S.; Fujioka, K.; Inoue, Y.; Kanaya, F.; Manome, Y.; Yamamoto, K. Cell-based in vitro blood-brain barrier model can rapidly evaluate nanoparticles' brain permeability in association with particle size and surface modification. Int. J. Mol. Sci. 2014, 15, 1812-1825.

31. Erceg, S.; Ronaghi, M.; Stojkovic, M. Human embryonic stem cell differentiation toward regional specific neural precursors. Stem Cells 2009, 27, 78-87.

32. Eriksson, P.S.; Perfilieva, E.; Bjork-Eriksson, T.; Alborn, A.M.; Nordborg, C.; Peterson, D.A.; Gage, F.H. Neurogenesis in the adult human hippocampus. Nat. Med. 1998, 4, 1313-1317.

33. Curtis, M.A.; Low, V.F.; Faull, R.L. Neurogenesis and progenitor cells in the adult human brain: A comparison between hippocampal and subventricular progenitor proliferation. Dev. Neurobiol. 2012, 72, 990-1005.

34. Kishi, Y.; Fujii, Y.; Hirabayashi, Y.; Gotoh, Y. HMGA regulates the global chromatin state and neurogenic potential in neocortical precursor cells. Nat. Neurosci. 2012, 15, 1127-1133. 
35. Song, M.; Moon, W.K.; Kim, Y.; Lim, D.; Song, I.C.; Yoon, B.W. Labeling efficacy of superparamagnetic iron oxide nanoparticles to human neural stem cells: Comparison of ferumoxides, monocrystalline iron oxide, cross-linked iron oxide (CLIO)-NH2 and tat-CLIO. Korean J. Radiol. 2007, 8, 365-371.

36. Soderstjerna, E.; Johansson, F.; Klefbohm, B.; Englund Johansson, U. Gold- and silver nanoparticles affect the growth characteristics of human embryonic neural precursor cells. PLoS One 2013, 8, e58211.

37. Sakai, N.; Matsui, Y.; Nakayama, A.; Tsuda, A.; Yoneda, M. Functional-dependent and Size-dependent Uptake of Nanoparticles in pc12. In Journal of Physics: Conference Series, 2011; IOP Publishing: Bristol, UK, 2011; p. 012049.

38. Ye, Y.; Liu, J.; Xu, J.; Sun, L.; Chen, M.; Lan, M. Nano-SiO 2 induces apoptosis via activation of p53 and Bax mediated by oxidative stress in human hepatic cell line. Toxicol. In Vitro 2010, 24, 751-758.

39. Kim, Y.J.; Yu, M.; Prark, H.O.; Yang, S.I. Comparative study of cytotoxicity, oxidative stress and genotoxicity induced by silica nanomaterials in human neuronal cell line. Mol. Cell. Toxicol. 2010, 6, 337-344.

40. Park, Y.-H.; Bae, H.C.; Jang, Y.; Jeong, S.H.; Lee, H.N.; Ryu, W.-I.; Yoo, M.G.; Kim, Y.-R.; Kim, M.-K.; Lee, J.K.; et al. Effect of the size and surface charge of silica nanoparticles on cutaneous toxicity. Mol. Cell. Toxicol. 2013, 9, 67-74.

41. Liu, X.; Ren, X.; Deng, X.; Huo, Y.; Xie, J.; Huang, H.; Jiao, Z.; Wu, M.; Liu, Y.; Wen, T. A protein interaction network for the analysis of the neuronal differentiation of neural stem cells in response to titanium dioxide nanoparticles. Biomaterials 2010, 31, 3063-3070.

42. Nabeshi, H.; Yoshikawa, T.; Matsuyama, K.; Nakazato, Y.; Matsuo, K.; Arimori, A.; Isobe, M.; Tochigi, S.; Kondoh, S.; Hirai, T.; et al. Systemic distribution, nuclear entry and cytotoxicity of amorphous nanosilica following topical application. Biomaterials 2011, 32, 2713-2724.

43. Kim, S.U. Human neural stem cells genetically modified for brain repair in neurological disorders. Neuropathology 2004, 24, 159-171.

44. Cho, T.; Bae, J.H.; Choi, H.B.; Kim, S.S.; McLarnon, J.G.; Suh-Kim, H.; Kim, S.U.; Min, C.K. Human neural stem cells: Electrophysiological properties of voltage-gated ion channels. Neuroreport 2002, 13, 1447-1452.

45. Lee, H.J.; Kim, K.S.; Kim, E.J.; Choi, H.B.; Lee, K.H.; Park, I.H.; Ko, Y.; Jeong, S.W.; Kim, S.U. Brain transplantation of immortalized human neural stem cells promotes functional recovery in mouse intracerebral hemorrhage stroke model. Stem Cells 2007, 25, 1204-1212.

46. Hanada, S.; Fujioka, K.; Futamura, Y.; Manabe, N.; Hoshino, A.; Yamamoto, K. Evaluation of anti-inflammatory drug-conjugated silicon quantum dots: Their cytotoxicity and biological effect. Int. J. Mol. Sci. 2013, 14, 1323-1334.

(C) 2014 by the authors; licensee MDPI, Basel, Switzerland. This article is an open access article distributed under the terms and conditions of the Creative Commons Attribution license (http://creativecommons.org/licenses/by/3.0/). 